\title{
Effects of a wide range of dietary forage-to- concentrate ratios on nutrient utilization and hepatic transcriptional profiles in limit- fed Holstein heifers
}

Haitao Shi ${ }^{1,2+}$, Jun Zhang ${ }^{1+}$, Shengli $\mathrm{Li}^{1}$, Shoukun $\mathrm{Ji}^{1}$, Zhijun Cao ${ }^{1}$, Hongtao Zhang ${ }^{1}$ and Yajing Wang ${ }^{1 *}$

\begin{abstract}
Background: Improving the efficiency of animal production is a relentless pursuit of ruminant producers. Energy utilization and partition can be affected by dietary composition and nutrient availability. Furthermore, the liver is the central metabolic intersection in cattle. However, the specific metabolic changes in the liver under conditions of limit-feeding remain unclear and require further study. The present study aimed to elucidate the effects of a wide range of dietary forage:concentrate ratios (F:C) on energy utilization, and identify potential changes in molecular metabolism by analyzing hepatic transcriptional profiles. Twenty-four half-sib Holstein heifers were fed four F:C diets (20:80, 40:60, 60:40, and 80:20 on a dry matter basis), with similar intake levels of metabolizable energy (ME) and crude protein. Liver biopsy samples were obtained and RNA sequencing was conducted to identify the hepatic transcriptomic changes. Moreover, the ruminal fermentation profiles, growth characteristics, and levels of metabolites in the liver and plasma of the heifers were monitored.

Results: The proportion of acetate showed a linear increase $(P<0.01)$ with increasing dietary forage levels, whereas the proportion of propionate showed a linear decline $(P \leq 0.01)$. Lower levels of average daily gain and feed efficiency $(P<0.01)$ were observed in heifers fed high levels of forage, with a significant linear response. Using the Short Time-series Expression Miner software package, the expression trends of significant differentially expressed genes (DEGs) were generally divided into 20 clusters, according to their dynamic expression patterns. Functional classification analysis showed that lipid metabolism (particularly cholesterol and steroid metabolism which were in line with the cholesterol content in the liver and plasma) was significantly increased with increasing dietary forage levels and slightly reduced by the $80 \%$ forage diet. Nine DEGs were enriched in the related pathways, namely HMGCS1, HMGCR, MSMO1, MVK, MVD, IDI1, FDPS, LSS, and DHCRT.
\end{abstract}

Conclusions: The ruminal fermentation and feed efficiency results suggest that different mechanisms of energy utilization might occur in heifers fed different F:C diets with similar levels of ME intake. Increased cholesterol synthesis from acetate might be responsible for the reduced efficiency of energy utilization in heifers fed high-forage diets.

Keywords: Energy utilization, Lipid metabolism, Forage level, Liver, Heifer, RNA-Seq

\footnotetext{
* Correspondence: yajingwang@cau.edu.cn

tEqual contributors

'State Key Laboratory of Animal Nutrition, Beijing Engineering Technology Research Center of Raw Milk Quality and Safety Control, College of Animal Science and Technology, China Agricultural University, No.2 Yuanmingyuan West Road, Haidian, Beijing 100193, People's Republic of China

Full list of author information is available at the end of the article
} 


\section{Background}

Ruminants are unique in their ability to convert large quantities of plant fiber into high-quality products, like meat and milk, for human consumption. With rapid growth in the human population, there is increasing demand for livestock products. Improving the efficiency of livestock production is a crucial requirement to meet this challenge and minimize any potential environmental impact [1]. Ruminants rely largely on the ruminal fermentation of feedstuffs by microorganisms to obtain nutrients, like volatile fatty acids (VFAs), proteins, and vitamins for maintenance, growth, and production [2]. Energy metabolism in heifers plays an important role in regulating feed efficiency, which ultimately affects growth, production performance, as well as the conception rate $[3,4]$.

Previous studies report that nutrient levels have a significant effect on metabolic activities and rate, and dietary forage:concentrate ratios (F:C) might affect visceral organ mass and/or metabolism, resulting in altered levels of available energy for weight gain and/or efficiency of gain [5-7]. Recently, limit-feeding of lowforage diets has been proposed as an effective method to improve energy efficiency in heifers, and had been explored by several researchers [8-10]. In most cases, limit-feeding means that heifers are fed low-forage diets to meet, but not exceed energy requirements for an appropriate level of average daily gain (ADG) [11, 12]. However, details of the associated physiological and metabolic mechanisms and changes remain to be further characterized.

The liver is the central metabolic intersection between portal-drained viscera (PDV) and the rest of body, and it accounts for $17 \%-25 \%$ of whole-body oxygen uptake or energy loss as heat, and only $1 \%-1.5 \%$ of total body weight $[6,13]$. As a central organ responsible for intermediary metabolism within the body, it is not surprising that the metabolic activities of liver would be affected by dietary composition and nutrient intake [14]. Coordination of the flux and inter-conversion of nutrients and metabolites in the liver might thus be altered by changes in the diet. The associated processes may be controlled by various means, including alterations of gene expression, enzyme activity, and the resultant nutrient fluxes that optimize liver function and nutrient interconversion [14]. Therefore, increased understanding of how the $\mathrm{F}: \mathrm{C}$ influences global hepatic gene expression profiles may lead to improved approaches to enhancing the efficiency of energy utilization in ruminant production systems. Furthermore, only two or three forage levels ( $76 \%$ vs. $24 \%$; $90 \%$ vs. $45 \%$; and $75 \%$ vs. $25 \%$ ) have been used in previous studies $[6,8,12]$. These designs however, do not provide a large enough range with which models can be developed to predict physiological variation, thereby leading to a better understanding of energy utilization in heifers.

High-throughput RNA sequencing (RNA-Seq) is rapidly emerging as a favored approach for transcriptomeoriented studies, and can be used to analyze changes in gene expression across the entire transcriptome $[15,16]$. With sensitive, unbiased detection of all expressed genes, this method has been successfully used in the identification of potential transcriptional mechanisms and components in bovine species subjected to different phenotypic and physiological changes. These include liver transcripts associated with dietary restriction [14], negative energy balance [17], and different levels of feed efficiency [18] in cattle. Therefore, RNA-Seq based transcriptomic profiling was used in the present study to identify the effects and underlying mechanism of four $\mathrm{F}: \mathrm{C}$ diets on hepatic gene expression profiles in heifers with an equal intake of metabolizable energy (ME). Moreover, the changes in ruminal fermentation, growth characteristics, and plasma metabolites were also analyzed.

\section{Methods}

Animals, experimental design, management, and diets

Animal care for the experiment complied with the Regulations for the Administration of Affairs Concerning Experimental Animals, National Committee of Science and Technology of China (14 November 1988) and Instructive Notions with Respect to Caring for Experimental Animals, Ministry of Science and Technology of China (13 September 2006). The animal procedures were approved by the Ethical Committee of the College of Animal Science and Technology of China Agricultural University.

Twenty-four half-sib Holstein heifers (8-10 months of age and $253 \pm 29 \mathrm{~kg}$ in body weight [BW] at the beginning of the study) from Beijing Sanyuan Lvhe Dairy Group (Beijing, China) were used for a 4-week feeding trial following a pre-experimental period of 4 weeks. Half-sib heifers were used to minimize the differences in genotype between individual animals. The animals were privately owned by the Beijing Sanyuan Lvhe Dairy Group and permissions for the animals to be used were obtained prior to initiation of the study. During the preexperimental period, all heifers were fed an adaptation diet containing $50 \%$ corn silage and $50 \%$ concentrate (on a dry matter (DM) basis; Additional file 1: Table S1). At the end of pre-experimental period, heifers were blocked by BW in a randomized complete block design, and assigned to four different $\mathrm{F}: \mathrm{C}$ diets $(20: 80,40: 60,60: 40$, and 80:20 on a DM basis, namely the S20, S40, S60, and S80 groups, respectively; Additional file 1: Table S1), with corn silage as the sole forage source. All diets were formulated to meet or exceed the NRC (2001) nutrient recommendations [19], and were provided as a total mixed ration 
(TMR) at levels calculated to provide a similar intake of $\mathrm{ME}$ and crude protein $(\mathrm{CP})$.

Heifers were individually fed a TMR twice daily at 12-h intervals (0700 and $1900 \mathrm{~h}$ ). Water was available ad libitum. Dry matter intake (DMI) for each heifer was recorded daily. Samples of individual feedstuffs and TMR were collected daily and stored at $-20{ }^{\circ} \mathrm{C}$. At the end of each week, the daily samples were pooled and subsamples were taken for chemical analysis.

\section{Ruminal sample collection, measurements, and growth characteristics}

At the end of the feeding period (day 28), rumen contents (100 mL/heifer) were collected using an oral stomach tube approximately $4 \mathrm{~h}$ after morning feeding, according to previously reported procedures [10]. Ruminal fluid that had been filtered (through four layers of cheesecloth) was stored at $-20{ }^{\circ} \mathrm{C}$, before the concentrations of $\mathrm{NH}_{3}-\mathrm{N}$ and VFAs were analyzed according to previously reported procedures [10, 20].

Body weight was measured on two consecutive days each week (approximately $1 \mathrm{~h}$ before morning feeding) and the mean values were used to adjust the TMR offered, and account for day-to-day variations [21]. The gut fill, ADG (after removing the effects of gut fill), and feed efficiency (FE, after removing effects of gut fill, FE = ADG/ DMI) were calculated, using prediction equations described by Williams et al. [22].

\section{Blood and liver sample collection, and metabolite measurements}

Blood samples were collected about $6 \mathrm{~h}$ after morning feeding from the jugular vein into 5-mL lithium heparin vacuum tubes (Hebei Xinle Medical, Shijiazhuang, China) on day 28 of the experimental period. All tubes were centrifuged at $3000 \mathrm{~g}$ at $4{ }^{\circ} \mathrm{C}$ for 15 min to obtain plasma, which was stored at $-20{ }^{\circ} \mathrm{C}$ until further analysis. The plasma activity/concentration levels of alanine aminotransferase (ALT), alkaline phosphatase, aspartate aminotransferase, $\beta$-hydroxybutyric acid, blood urea nitrogen, glucose, lactate dehydrogenase, low-density lipoprotein cholesterol (LDL-C), total amino acids, total bilirubin, total cholesterol (TC), total triglyceride (TG), total protein, and non-esterified fatty acids were analyzed, using a Clinical HITACHI (7160) Automatic Analyzer (Hitachi Limited, Tokyo, Japan) with kits supplied by an instrumentation laboratory. Plasma concentration of highdensity lipoprotein cholesterol (HDL-C) was measured using an immunoinhibition method (kits from Beijing Beijian Xinchuangyuan Biotechnology Ltd.). Plasma levels of very low-density lipoprotein cholesterol (VLDL-C) were measured, using enzyme-linked immunosorbent assay (ELISA) kits (Shanghai Huole Biotechnology Ltd.), according to the manufacturer's instructions.
Liver biopsies from each heifer were obtained immediately after blood sampling by percutaneous needle biopsy, as previously described [23, 24]. Briefly, the skin was shaved and disinfected and the area through the skin and body wall was anesthetized with $2 \%$ lignocaine (Shanghai Harvest Pharmaceutical Co., Ltd., Shanghai, China). A stab incision was made through the skin in the right 11th intercostals space at the level of the greater trochanter, through which a biopsy needle was inserted into the liver and around 500-1000 mg liver tissue was collected. All biopsies were then rinsed in saline and immediately frozen in liquid $\mathrm{N}$ until further analysis. For metabolite analysis, $0.9 \mathrm{~mL}$ absolute ethyl alcohol was added to a 100-mg liver sample. The mixture was homogenized with a microelectric homogenizer (Kontes) for $30 \mathrm{~s}$, and then centrifuged at $2000 \mathrm{~g}$ at $4{ }^{\circ} \mathrm{C}$ for 20 min to obtain a suspension. The TC and TG concentrations in the liver were analyzed using a commercially available enzymatic kit (Nanjing Jiancheng Bioengineering Institute, Nanjing, China).

\section{Liver RNA isolation, sequencing, and sequence data processing}

Total RNA from liver biopsies was isolated using the QIAzol Lysis Reagent (Qiagen, Hilden, Germany), followed by purification on the miRNeasy mini column (miRNeasy Mini Kit, Qiagen, Hilden, Germany), according to the manufacturer's protocols. The RNA quality and purity were checked using an ND-100 NanoDrop spectrophotometer (NanoDrop Technologies, Wilmington, DE, USA). Any RNA integrity number (RIN) $>8.0$ was deemed to be of sufficiently high quality. RNA degradation and contamination were monitored on $1.0 \%$ agarose gels.

Briefly, $2.5 \mu \mathrm{g}$ of total RNA was enriched by Poly-A using the NEBNext Poly (A) mRNA Magnetic Isolation Module (NEB, E7490S). A transcriptome library was constructed for sequencing, according to the protocols of the NEBNext Ultra RNA Library Prep Kit for Illumina (NEB, E7530S) and NEBNext Multiplex Oligos for Illumina (NEB, E7500S). The prepared library was quantified using the KAPA Library Quantification Kit-Illumina GA Universal (Kapa, KK4824), and subjected to $1.8 \%$ agarose gel electrophoresis to be validated for quality. The library products were sequenced via an Illumina HiSeq 2500 sequencer. Both library building and sequencing were performed by CapitalBio Corporation (Beijing, China).

Raw reads were cleaned by removing adapter and primer sequences, reads containing $<10 \mathrm{nt}$, and low-quality reads (more than half of the reads with a phred base quality score of $<5$ ) from the raw data. Ribosome RNA sequences were filtered from the raw fragments. All downstream analyses were based on the clean reads. 
An index of the reference genome was built using Bowtie v1.1.2, and paired-end clean reads for each individual were aligned to the bovine reference genome (UMD3.1) using TopHat v2.1.0, and then assembled using the Cufflinks package $[14,25]$. The differentially expressed genes (DEGs) were detected by Cuffdiff, which is included in the Cufflinks package. The commonly used fragments per kilobase of exon per million fragments mapped (FPKM) in pair-end sequencing experiments was incorporated in two normalization steps; i.e. the number of fragments were normalized by the transcript's length and total yield of the fragments to ensure accurate quantification of the gene's expression [25]. Genes with a false discovery rate (FDR, $q$-value) $\leq 0.05$ and a fold change (FC) greater than 1.5 were considered DEGs.

\section{Gene ontology and pathway analysis}

The overall DEGs ( $q$-value $\leq 0.05$ and FC $\geq 1.5$ ) were analyzed for enrichment of Gene Ontology (GO) terms (biological process (BP), molecular function (MF) and cellular component (CC)) and Kyoto Encyclopedia of Genes and Genomes database (KEGG) pathways using DAVID Bioinformatics Resources [26]. For GO analysis, values of $P \leq 0.05$ identified differentially enriched terms, and genes with a $q$-value $<0.05$ among the DEGs were considered significantly enriched. Significant differentially enriched KEGG pathways were considered as those with a value of $P \leq 0.05$.

\section{Short time-series expression miner (STEM) analysis}

Assignments of DEGs to temporal expression profiles and detection of statistically enriched gene families within each profile was conducted using STEM v1.3.8 [27], with the maximum number of model profiles set to 20 , and maximum unit change in model profiles between time points set to 2 . The expression data (FPKM value) were normalized to $0[\log 2(\mathrm{~S} 20 / \mathrm{S} 20)], \log 2(\mathrm{~S} 40 /$ $\mathrm{S} 20), \log 2(\mathrm{~S} 60 / \mathrm{S} 20)$, and $\log 2(\mathrm{~S} 80 / \mathrm{S} 20)$ when input to STEM. Each gene was assigned to the closest profile using a Pearson correlation-based distance metric. To determine the significance level for a given transcriptome profile, a permutation-based test was used to quantify the expected number of genes that would be assigned to each profile [28]. The $P$-value derived from STEM analysis was corrected for multiple hypothesis testing, using a $q$-value $<0.05$. To understand further the biological functions of DEGs clustered in STEM, GO and KEGG analyses were also performed using DAVID Bioinformatics Resources [26].

\section{The quantitative real-time PCR (qRT-PCR) protocol}

To validate the repeatability and reproducibility of gene expression data obtained by RNA sequencing in the Holstein heifers, quantitative real-time PCR was carried out on five randomly selected DEGs (DHCR7, LSS, HSPB1, ATF4, and GOT1) using the total RNA used for RNA-Seq. The PrimeScript ${ }^{\text {Tw }}$ RT Master Mix (Takara, Dalin, China) was used to synthesize first-strand cDNA according to the manufacturer's protocol. Primers were designed by Primer5 (http://www.premierbiosoft.com/ primerdesign/index.html), and the sequences are presented in Additional file 1: Table S2. The qRT-PCR was carried out in triplicate with a final volume of $10 \mu \mathrm{L}$ using the $\mathrm{SYBR}^{\circ}$ Premix Ex Taq ${ }^{\mathrm{Tm}}$ II (Takara, Dalin, China) on the QuantStudio ${ }^{\text {tx }} 6$ Flex system (Life Technologies, USA), following the manufacturer's protocol. The relative expression of target genes was normalized to the expression of GAPDH and $\beta$-actin, and calculated using the $2^{-\Delta \Delta C t}$ method [29-31].

\section{Statistical analyses}

Data for ruminal fermentation parameters, growth characteristics, liver and plasma metabolites, and qRT-PCR were analyzed in a randomized complete block design using the PROC MIXED procedure of the SAS software (SAS Institute Inc., Cary, NC, USA). The model included treatment and block as fixed effects. Results were reported as least squares means, and compared using the Tukey's test. Contrasts were used to test the linear, quadratic, and cubic changes effected by increasing levels of dietary forage. Significant differences were declared at $P \leq 0.05$, and trends were reported at $0.05<P<0.10$.

\section{Results}

Ruminal fermentation parameters and growth characteristics The concentration of $\mathrm{NH}_{3}-\mathrm{N}$ showed a quadratic decline $(P<0.01)$ in the $S 60$ group, which had the lowest value among all treatments. Ruminal proportions of acetate, and the ratio of acetate:propionate (A:P) showed a linear increase $(P<0.01)$ with increasing levels of forage in the diets (Table 1). The proportions of propionate and butyrate showed a linear decline $(P \leq 0.01)$ with increasing dietary forage levels. The proportions of isobutyrate showed a quadratic increase $(P=0.02)$, with the $\mathrm{S} 60$ group yielding the highest value with increasing dietary forage levels. The proportions of isovalerate were cubically influenced $(P=0.04)$ with increasing dietary forage levels.

By the end of the experiment, no significant differences were found in BW among the treatments (Table 2). The final gut fill was calculated and showed a linear increase $(P<0.01)$ with increasing dietary forage levels, whereas the ADG and FE showed a linear decline $(P<0.01)$.

\section{Liver and plasma metabolites}

As shown in Table 3, liver concentrations of TC and TG were cubically changed $(P \leq 0.034)$ with increasing dietary forage levels; the $S 60$ group yielded the highest 
Table 1 Effects of dietary forage levels on ruminal fermentation in Holstein heifers

\begin{tabular}{|c|c|c|c|c|c|c|c|c|c|}
\hline \multirow[t]{2}{*}{ Items } & \multicolumn{4}{|c|}{ Forage levels (\% of diet DM) } & \multirow[t]{2}{*}{ SEM $^{f}$} & \multicolumn{4}{|l|}{$P$-value } \\
\hline & 20 & 40 & 60 & 80 & & Treatment & Linear & Quadratic & Cubic \\
\hline $\mathrm{NH}_{3}-\mathrm{N}, \mathrm{mg} / \mathrm{dL}$ & $8.27^{\mathrm{a}}$ & $3.93^{b}$ & $2.22^{\mathrm{b}}$ & $2.40^{\mathrm{b}}$ & 0.583 & $<0.01$ & $<0.01$ & $<0.01$ & 0.78 \\
\hline TVFAs ${ }^{\mathrm{e}}, \mathrm{mM}$ & 94.64 & 92.49 & 89.53 & 86.10 & 1.806 & 0.43 & 0.11 & 0.87 & 0.98 \\
\hline \multicolumn{10}{|c|}{ VFAs, molar $\%$ of TVFAs } \\
\hline Acetate & $53.85^{c}$ & $58.04^{b c}$ & $62.48^{\mathrm{ab}}$ & $65.97^{\mathrm{a}}$ & 1.135 & $<0.01$ & $<0.01$ & 0.81 & 0.85 \\
\hline Propionate & $25.44^{\mathrm{a}}$ & $23.31^{\mathrm{ab}}$ & $22.10^{\mathrm{ab}}$ & $20.99^{b}$ & 0.624 & 0.04 & 0.01 & 0.63 & 0.86 \\
\hline Butyrate & $16.91^{\mathrm{a}}$ & $12.42^{b}$ & $11.05^{b}$ & $9.69^{b}$ & 0.688 & $<0.01$ & $<0.01$ & 0.09 & 0.43 \\
\hline Valerate & 0.56 & 1.08 & 0.58 & 0.52 & 0.100 & 0.11 & 0.42 & 0.11 & 0.08 \\
\hline Isobutyrate & 0.93 & 2.16 & 2.29 & 1.24 & 0.226 & 0.10 & 0.59 & 0.02 & 0.97 \\
\hline Isovalerate & 2.27 & 2.99 & 1.49 & 1.59 & 0.223 & 0.05 & 0.06 & 0.43 & 0.04 \\
\hline$A: P^{g}$ & $2.16^{b}$ & $2.53^{\mathrm{ab}}$ & $2.89^{\mathrm{ab}}$ & $3.18^{\mathrm{a}}$ & 0.115 & $<0.01$ & $<0.01$ & 0.81 & 0.96 \\
\hline
\end{tabular}

$(n=6)$

${ }^{a-c}$ Means within a row with different superscripts differ significantly $(P<0.05)$

'TVFAs total volatile fatty acids

${ }^{S} \mathrm{SEM}$ standard error of the mean

${ }^{\mathrm{g}} \mathrm{A}: \mathrm{P}$ acetate:propionate

values. Plasma concentration of LDL-C showed a linear increase $(P=0.001)$ with increasing dietary forage levels, whereas the concentration of urea showed a linear decline $(P<0.001)$. Plasma concentration of VLDL$\mathrm{C}$ showed a linear $(P<0.001)$ and cubic $(P<0.001)$ response with increasing dietary forage levels; whereas that of TC tended towards a linear increase $(P=0.070)$. Other measured plasma metabolites showed no significant differences among treatments.

\section{Sequencing and characterization of the bovine liver transcriptome}

As shown in Table 4, the cDNA libraries of 24 liver biopsy samples from heifers fed the four experimental diets were sequenced (125 bp paired-end strategy), and in total $39,273,652$ to $55,427,092$ paired-end reads were obtained. After filtering low-quality reads and adapters from raw fragments, $38,637,820$ to $54,562,265$ highquality clean reads in each sample were obtained.
Among the high-quality reads, $91.88 \%-93.87 \%$ had basecall quality at Q30 (proportion of bases with a phred base-quality score $>30$ ); and $99.69 \%-99.85 \%$ at Q20 (proportion of bases with a phred base-quality score > 20). Alignment of sequence reads against the bovine genome UMD3.1 yielded $86.87 \%-90.60 \%$ of aligned reads across the 24 samples. Among these, $81.52 \%-83.88 \%$ were uniquely aligned reads that were used for further analysis, to verify the reliability of the results.

All sequencing data (fastq files) generated in the present study are available in the NCBI Sequence Read Archive (SRA) (https://www.ncbi.nlm.nih.gov/sra/) under accession number SRP110260.

When selected gene expression levels between qRTPCR and RNA-Seq platforms were compared, a strong average correlation $(\mathrm{r}=0.88)$ was observed, confirming the high reproducibility of the data. For all five genes, the fold changes among treatments in qRT-PCR were consistent with those in the RNA-Seq data (Fig. 1).

Table 2 Effects of dietary forage levels on growth characteristics

\begin{tabular}{|c|c|c|c|c|c|c|c|c|c|}
\hline \multirow[t]{2}{*}{ Items $^{e}$} & \multicolumn{4}{|c|}{ Forage levels (\% of diet DM) } & \multirow[t]{2}{*}{$\mathrm{SEM}^{\mathrm{f}}$} & \multicolumn{4}{|l|}{$P$-value } \\
\hline & 20 & 40 & 60 & 80 & & Treatment & Linear & Quadratic & Cubic \\
\hline Initial BW, kg & 262.5 & 263.8 & 263.7 & 262.3 & 6.096 & 0.96 & & & \\
\hline Initial gut fill ${ }^{9}, \mathrm{~kg}$ & 38.12 & 38.81 & 39.22 & 39.43 & 0.448 & 0.22 & & & \\
\hline Final BW, kg & 284.2 & 287.0 & 288.7 & 290.5 & 6.330 & 0.40 & 0.10 & 0.82 & 0.91 \\
\hline Final gut fill ${ }^{9}, \mathrm{~kg}$ & $29.89^{d}$ & $38.83^{c}$ & $47.80^{\mathrm{b}}$ & $56.91^{\mathrm{a}}$ & 0.645 & $<0.01$ & $<0.01$ & 0.90 & 0.97 \\
\hline$A D G^{9}, \mathrm{~kg} / \mathrm{d}$ & $1.07^{\mathrm{a}}$ & $0.83^{b}$ & $0.59^{c}$ & $0.38^{c}$ & 0.051 & $<0.01$ & $<0.01$ & 0.72 & 0.88 \\
\hline $\mathrm{FE}^{\mathrm{g}}$ & $0.24^{\mathrm{a}}$ & $0.18^{\mathrm{b}}$ & $0.12^{c}$ & $0.07^{d}$ & 0.009 & $<0.01$ & $<0.01$ & 0.32 & 0.97 \\
\hline
\end{tabular}

$(n=6)$

${ }^{\text {a-d }}$ Means within a row with different superscripts differ significantly $(P<0.05)$

${ }^{\mathrm{e}} B W$ body weight, $A D G$ average daily gain, $F E$ feed efficiency; $D M$ dry matter

${ }^{\mathrm{S}} \mathrm{BEM}$ standard error of the mean

${ }^{9} \mathrm{ADG}=($ final BW - final gut fill) - (initial BW - initial gut fill); FE = ADG/DMI, calculated according to Williams et al. [22] 
Table 3 Influence of dietary forage levels on liver and plasma metabolites in Holstein heifers

\begin{tabular}{|c|c|c|c|c|c|c|c|c|c|}
\hline \multirow[t]{2}{*}{ Items $^{c}$} & \multicolumn{4}{|c|}{ Forage levels (\% of diet DM) } & \multirow[t]{2}{*}{$\mathrm{SEM}^{d}$} & \multicolumn{4}{|l|}{$P$-value } \\
\hline & 20 & 40 & 60 & 80 & & Treatment & Linear & Quadratic & Cubic \\
\hline \multicolumn{10}{|l|}{ Liver } \\
\hline $\mathrm{TC}, \mathrm{mg} / \mathrm{g}$ of liver tissue & $1.39^{\mathrm{ab}}$ & $1.40^{\mathrm{ab}}$ & $2.53^{\mathrm{a}}$ & $1.19^{\mathrm{b}}$ & 0.170 & 0.029 & 0.710 & 0.056 & 0.026 \\
\hline $\mathrm{TG}, \mu \mathrm{mol} / \mathrm{g}$ of liver tissue & 3.67 & 3.99 & 6.72 & 3.83 & 0.397 & 0.027 & 0.369 & 0.056 & 0.034 \\
\hline \multicolumn{10}{|l|}{ Plasma } \\
\hline Total protein, g/L & 71.71 & 71.32 & 71.57 & 71.60 & 0.961 & 0.993 & 0.989 & 0.831 & 0.843 \\
\hline Glucose, $\mathrm{mmol} / \mathrm{L}$ & 4.54 & 4.53 & 4.40 & 4.49 & 0.126 & 0.856 & 0.624 & 0.711 & 0.549 \\
\hline Lactate Dehydrogenase, U/L & 996.43 & 944.55 & 934.24 & 951.20 & 54.359 & 0.857 & 0.557 & 0.536 & 0.954 \\
\hline Aspartate Aminotransferase, $U / L$ & 68.06 & 71.18 & 65.03 & 73.67 & 4.084 & 0.490 & 0.567 & 0.510 & 0.207 \\
\hline$A L T, U / L$ & $36.78^{b}$ & $40.06^{b}$ & $44.07^{\mathrm{ab}}$ & $53.60^{\mathrm{a}}$ & 2.312 & 0.007 & $<0.001$ & 0.197 & 0.650 \\
\hline $\mathrm{TC}, \mathrm{mmol} / \mathrm{L}$ & 2.46 & 2.74 & 2.92 & 2.81 & 0.141 & 0.169 & 0.070 & 0.188 & 0.773 \\
\hline $\mathrm{TG}, \mathrm{mmol} / \mathrm{L}$ & 0.37 & 0.31 & 0.44 & 0.39 & 0.051 & 0.407 & 0.451 & 0.904 & 0.136 \\
\hline Alkaline Phosphatase, mmol/L & 141.94 & 129.10 & 139.79 & 157.86 & 13.350 & 0.518 & 0.343 & 0.265 & 0.790 \\
\hline Urea, mmol/L & $3.33^{\mathrm{a}}$ & $3.19^{\mathrm{a}}$ & $3.09^{\mathrm{ab}}$ & $2.55^{\mathrm{b}}$ & 0.113 & 0.001 & $<0.001$ & 0.097 & 0.362 \\
\hline$\beta$-hydroxybutyric acid, mmol/L & 0.13 & 0.12 & 0.11 & 0.12 & 0.005 & 0.204 & 0.057 & 0.493 & 0.520 \\
\hline Total amino acids, mmol/L & 3.70 & 3.91 & 4.57 & 3.30 & 0.473 & 0.324 & 0.803 & 0.140 & 0.275 \\
\hline Nonesterified Fatty Acid, mmol/L & 0.47 & 0.46 & 0.45 & 0.44 & 0.014 & 0.531 & 0.162 & 0.783 & 0.820 \\
\hline Total Bilirubin, $\mu \mathrm{mol} / \mathrm{L}$ & 12.02 & 11.83 & 11.22 & 12.52 & 0.581 & 0.486 & 0.739 & 0.222 & 0.380 \\
\hline VLDL-C, $\mathrm{mmol} / \mathrm{L}$ & 0.53 & 0.75 & 0.58 & 0.94 & 0.060 & 0.001 & 0.002 & 0.259 & 0.003 \\
\hline $\mathrm{LDL}-\mathrm{C}, \mathrm{mmol} / \mathrm{L}$ & 0.58 & 0.58 & 0.96 & 0.98 & 0.085 & 0.004 & 0.001 & 0.893 & 0.077 \\
\hline $\mathrm{HDL}-\mathrm{C}, \mathrm{mmol} / \mathrm{L}$ & 1.63 & 1.71 & 1.63 & 1.52 & 0.094 & 0.579 & 0.348 & 0.326 & 0.801 \\
\hline
\end{tabular}

${ }^{\mathrm{a}-\mathrm{b}}$ Means within a row with different superscripts differ significantly $(P<0.05)$

${ }^{c} A L T$ alanine aminotransferase, $T C$ total cholesterol, $T G$ total triglycerides, VLDL-C very low-density lipoprotein cholesterol, $L D L-C$ low-density lipoprotein cholesterol, $H D L-C$ high-density lipoprotein cholesterol

${ }^{\mathrm{d}} \mathrm{SEM}$ standard error of the mean

Table 4 Statistics for RNA-Seq reads from liver biopsy, and alignment information with Tophat ${ }^{\mathrm{a}}$ (group means)

\begin{tabular}{|c|c|c|c|c|}
\hline \multirow[t]{2}{*}{ Mapping summary } & \multicolumn{4}{|c|}{ Forage levels (\% of diet DM) } \\
\hline & 20 & 40 & 60 & 80 \\
\hline Total reads (raw reads) & $45,397,012$ & $44,701,037$ & $43,415,394$ & $45,897,090$ \\
\hline Clean reads & $44,679,767$ & $43,983,934$ & $42,714,824$ & $45,155,970$ \\
\hline Statistic for clean reads: Q20 ${ }^{\mathrm{b}}$ & $99.79 \%$ & $99.83 \%$ & $99.83 \%$ & $99.83 \%$ \\
\hline Statistic for clean reads: Q30 ${ }^{C}$ & $92.88 \%$ & $92.94 \%$ & $92.80 \%$ & $92.80 \%$ \\
\hline Statistic for clean reads: GC content & $44.17 \%$ & $45.00 \%$ & $44.00 \%$ & $44.00 \%$ \\
\hline Statistic for clean reads: Seq-Dupl-level ${ }^{d}$ & $85.18 \%$ & $83.91 \%$ & $84.30 \%$ & $82.52 \%$ \\
\hline Mapping rate & $89.72 \%$ & $90.20 \%$ & $90.03 \%$ & $89.97 \%$ \\
\hline Total mapped reads & $40,109,810$ & $39,668,475$ & $38,458,347$ & $40,641,575$ \\
\hline Multiple mapped reads & $2,938,690$ & $2,958,931$ & $2,849,620$ & $3,070,914$ \\
\hline Unique mapped reads & $37,171,120$ & $36,709,544$ & $35,608,727$ & $37,570,661$ \\
\hline Junction mapped reads & $19,339,604$ & $18,902,568$ & $18,610,456$ & $19,784,290$ \\
\hline Statistic for clean reads: error rate & $0.29 \%$ & $0.30 \%$ & $0.30 \%$ & $0.31 \%$ \\
\hline
\end{tabular}

${ }^{\mathrm{a}}$ Bovine genome UMD3.1 was used for the alignment

${ }^{\mathrm{b}} \mathrm{Q} 20$, the proportion of bases with a phred base-quality score $>20$; i.e., the proportion of read bases with an error rate less than $1 \%$

${ }^{\mathrm{C}} \mathrm{Q} 30$, the proportion of bases with a phred base-quality score $>30$; i.e., the proportion of read bases with an error rate less than $0.1 \%$

${ }^{\mathrm{d}}$ Seq-Dupl-level, sequence duplication level 


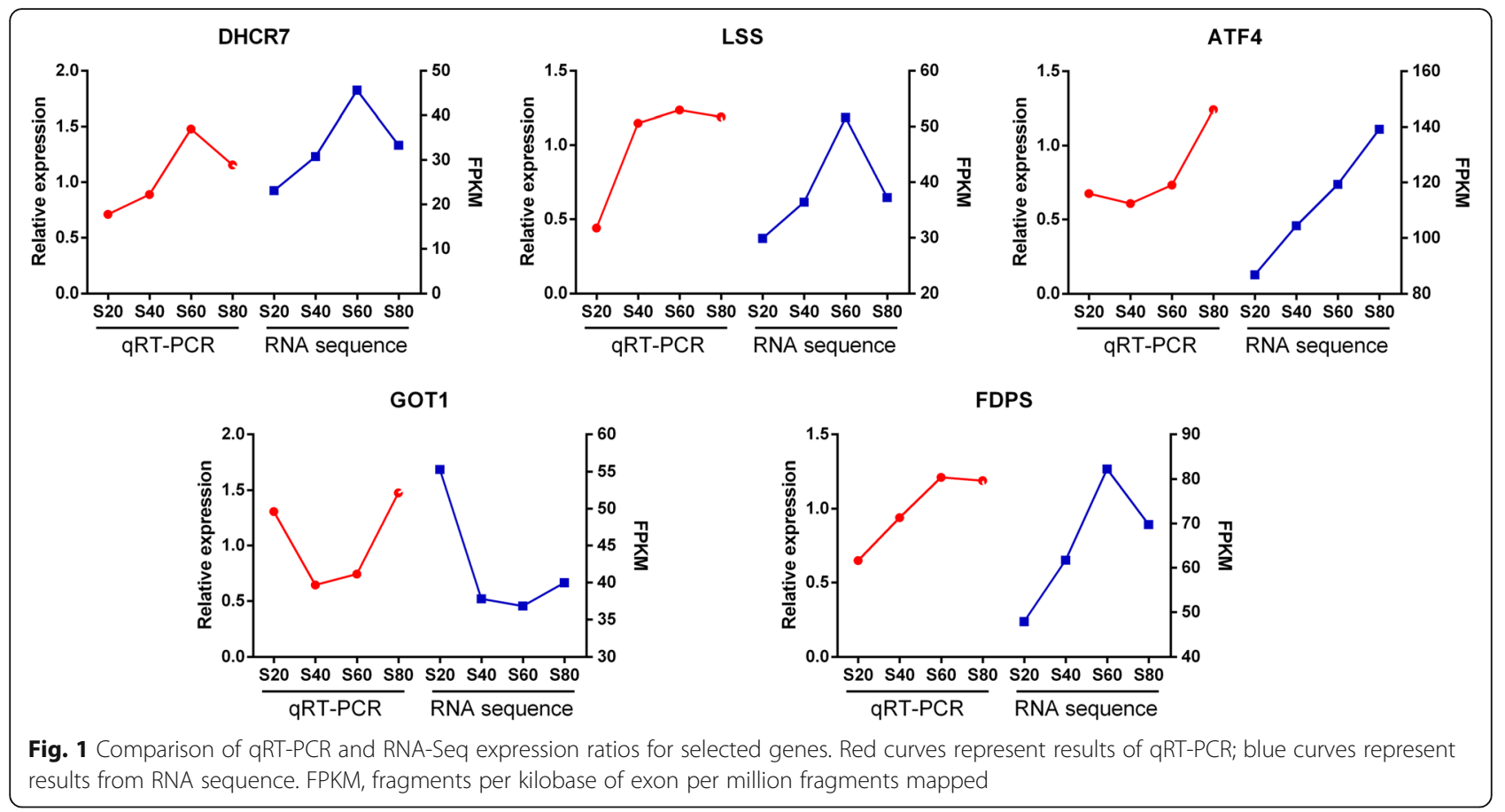

\section{Differential gene expression}

A total of 10,005 unigenes were detected in the bovine liver. In addition, 532 DEGs were identified among the treatment groups. The number of DEGs between groups were 81 (S20 vs. S40), 225 (S20 vs. S60), 258 (S20 vs. S80), 112 (S40 vs. S60), 161 (S40 vs. S80), and 138 (S60 vs. S80). The details of the DEGs, including gene IDs, symbols, descriptions, and statistical information are shown in Additional file 2: Table S4. The heatmap of the DEGs was generated by hierarchical cluster analysis of gene expression traits (Fig. 2). The resultant heat map revealed a clear bifurcation of treatments into two broad clusters that were generally segregated into low-forage (S20 and S40, similarity =0.7) and highforage (S60 and S80, similarity $=0.9)$ dietary treatments.

\section{Functional analysis of all DEGs among four dietary treatments}

The GO analysis revealed that 76,14 , and eight different $(P \leq 0.05)$ terms were enriched for $\mathrm{BP}, \mathrm{MF}$, and $\mathrm{CC}$, respectively (Additional file 1: Table S5). Among them, five BP-terms related to lipid metabolism, namely cholesterol biosynthetic process, sterol biosynthetic process, lipid biosynthetic process, cholesterol metabolic process, and sterol metabolic process, as well as one other BP (oxidation reduction) were significantly ( $q$-value $\leq 0.05$ ) enriched among the four dietary treatments (Table 5). The DEGs related to lipid metabolism were PCK1, MSMO1, FDPS, IDI1, MVK, SOAT2, PTGS1, CYP11A1, HMGCR, MOGAT1, P2RX7, HMGCS1, MVD, FADS2, DHCR7, $A C A C A, L S S$, and $A G M O$. Nine significant pathways were enriched $(P \leq 0.05)$ in the KEGG analysis, most of which were related to lipid, amino acid, and carbohydrate metabolic pathways (Fig. 3).

Expression pattern and functional analysis of DEGs involved in the significant gene expression profiles

Figure 4 shows that three gene expression profiles (17, 19 , and 4) were significant, among 20 candidate profiles. The abundance of DEGs in profile 17 increased monotonically with increasing dietary forage levels (112 DEGs; $\left.P=3 \times 10^{-40}\right)$. Expression of genes in profile 19 was upregulated when dietary forage levels increased from $20 \%$ to $60 \%$, and then downregulated when dietary forage levels increased from $60 \%$ to $80 \%$ (73 DEGs; $\left.P=2 \times 10^{-11}\right)$. Expression levels of DEGs clustered in profile 4 decreased monotonically with increasing dietary forage levels (47 DEGs; $P=4 \times 10^{-5}$ ). The list of DEGs and their expression levels in the three profiles are shown in Additional file 1: Table S5.

Results showed that DEGs clustered in profile 17 were enriched in $26 \mathrm{GO}$ categories $(P \leq 0.05)$, including 21 BP-terms, one CC-Term, and four MF-Terms (Fig. 5). Furthermore, KEGG pathway analysis showed that the p53 signaling pathway (three DEGs; $P=0.038$ ) and mitogen-activated protein kinase (MAPK) signaling pathway (five DEGs; $P=0.038$ ) were significantly enriched by DEGs in profile 17 (Table 6).

The DEGs in expression profile 19 were enriched $(P \leq$ 0.05) in 12 BP-terms and two CC-Terms (Fig. 5). Among them, the BP-terms involved in cholesterol biosynthetic process, sterol biosynthetic process, steroid biosynthetic 


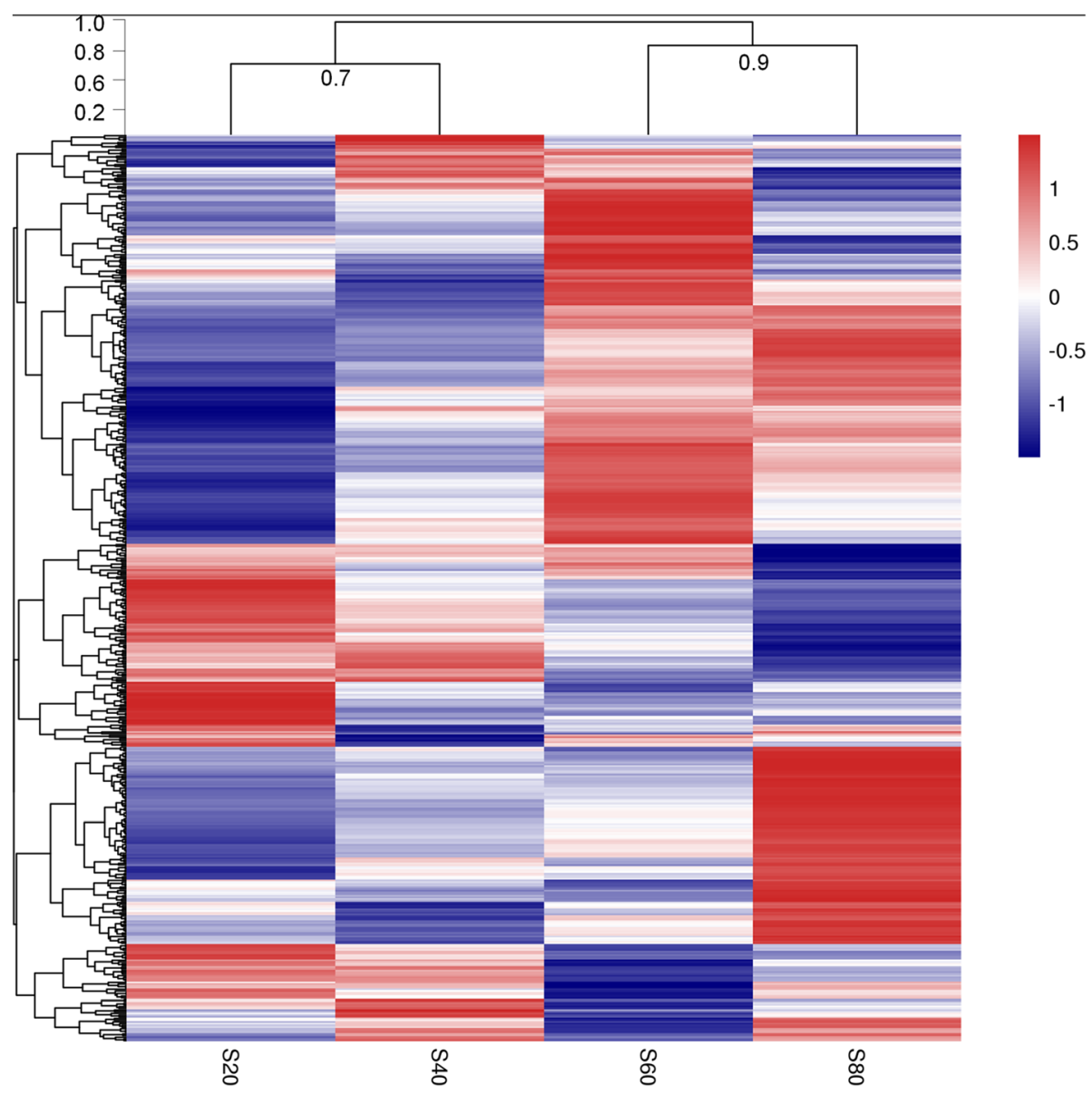

Fig. 2 Heatmap showing hierarchical clustering of 532 differentially expressed genes among treatments. The log2 ratio values of DEG abundance were used for hierarchical cluster analysis with the R pheatmap package. Red and blue indicate relative over- or under-expression of genes, respectively. Dietary treatments were corn silage-based diets that consisted of $20 \%, 40 \%, 60 \%$, and $80 \%$ corn silage (on a DM basis, namely the S20, S40, S60, and S80 groups)

process, cholesterol metabolic process, sterol metabolic process, isoprenoid biosynthetic process, lipid biosynthetic process, steroid metabolic process, and isoprenoid metabolic process were significantly enriched $(q$-value $\leq 0.05)$ (Fig. 5). In addition, the terpenoid backbone biosynthesis pathway (six DEGs; $P=2.68 \times 10^{-9}$ ) and steroid biosynthesis pathway (four DEGs; $P=5.75 \times 10^{-5}$ ) were significantly enriched by DEGs in profile 19 in KEGG (Table 6).

Only two BP-terms (retinoic acid receptor signaling pathway and intracellular receptor-mediated signaling pathway) and two MF-terms (glutathione transferase

Table 5 Gene Ontology analysis of differentially expressed genes (only significant terms listed)

\begin{tabular}{lllll}
\hline GO ID $^{\text {a }}$ & GO Terms & Counts $^{\text {b }}$ & $P$-value & $q$-value \\
\hline BP-GO:0006695 & cholesterol biosynthetic process & 7 & $4.64 \mathrm{E}-06$ & 0.007729 \\
BP-GO:0016126 & sterol biosynthetic process & 7 & $9.26 \mathrm{E}-06$ & 0.015432 \\
BP-GO:0008610 & lipid biosynthetic process & 17 & $9.88 \mathrm{E}-06$ & 0.016469 \\
BP-GO:0055114 & oxidation reduction & 32 & $1.31 \mathrm{E}-05$ & 0.021806 \\
BP-GO:0008203 & cholesterol metabolic process & 9 & $1.41 \mathrm{E}-05$ & 0.023523 \\
BP-GO:0016125 & sterol metabolic process & 9 & $2.79 \mathrm{E}-05$ & 0.046546 \\
\hline
\end{tabular}

\section{${ }^{a} G O$ Gene Ontology}

${ }^{\mathrm{b}}$ Number of differentially expressed genes 


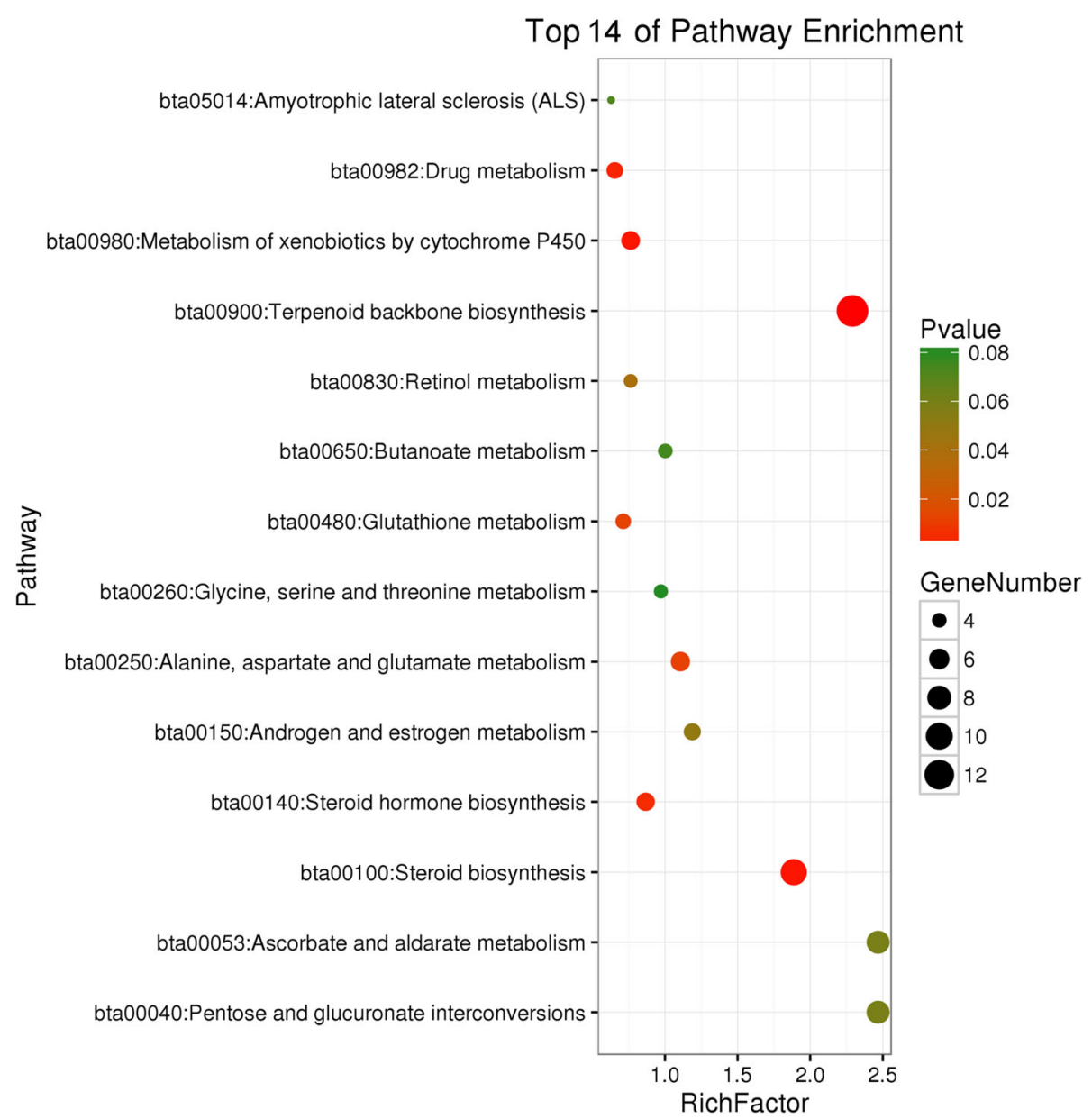

Fig. 3 KEGG pathway enrichment analysis of differentially expressed genes (top 14 pathways listed according to $P$-value)

activity and transaminase activity) were enriched $(P \leq$ 0.05 ) by DEGs clustered in profile 4 (Fig. 5 ), and no significant KEGG pathway was enriched.

\section{Discussion}

\section{Animal performance}

Consistent with previous studies [8,12], all groups had a similar intake of ME and $\mathrm{CP}$, indicating that the limitfeeding model was successfully established in the present study. As the amount of feed offered was determined by the ME of the diets, the DMI was increased with increasing dietary forage levels (Additional file 1: Table S2). As less rumen degradable protein was provided, ruminal $\mathrm{NH}_{3}-\mathrm{N}$ concentration was reduced for the highforage treatment compared to the low-forage treatment $(P<0.01$, Table 1$)$, which is consistent with the findings of previous studies $[8,12]$. In ruminants, VFAs are the predominant source of energy that is absorbed from dietary sources [13]. The chemical composition of substrates could affect the molar ratios of ruminal VFAs, and the fermentation of structural carbohydrates could yield higher levels of acetate and lower levels of propionate as compared to the fermentation of starch [32]. In this study, the proportions of acetate were increased, whereas the proportions of propionate and butyrate were reduced with increasing dietary forage levels, which is consistent with the findings of other studies $[9,12]$. After absorption, VFAs are mainly metabolized in PDV and the liver; acetate is mainly converted to fatty acids and propionate is mainly converted to glucose [33, 34] . The net release of acetate and propionate in the rumen accounted for about $70 \%$ and $55 \%$ of their portal net releases, respectively [34]. Previous studies suggest that propionate could be the original precursor of about $27 \%-54 \%$ of circulating glucose [35]. In comparison to acetate, the energy utilization efficiency of propionate was greater $(52.3 \%-56.3 \%$ vs. $32.9 \%-44.4 \%)$. This apparently lower efficiency of acetate might be responsible for the depression in energy utilization of high-fiber feeds $[36,37]$. The greater percentage of propionate combined with the similar levels of total volatile fatty acids (TVFAs) in the rumen indicate that an increased supply 
Profiles ordered based on the p-value significance of number of genes assigned versus expected
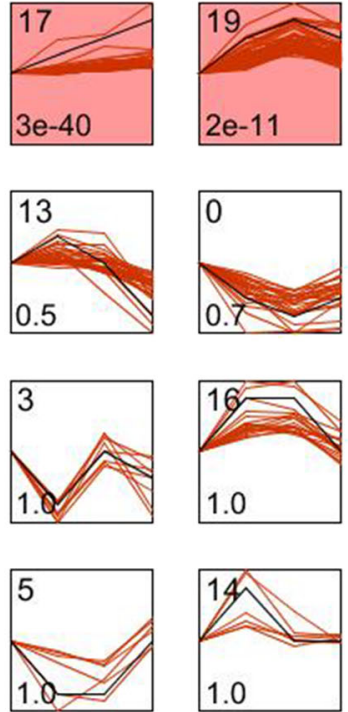
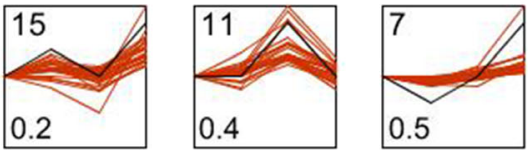

$4 e-5$
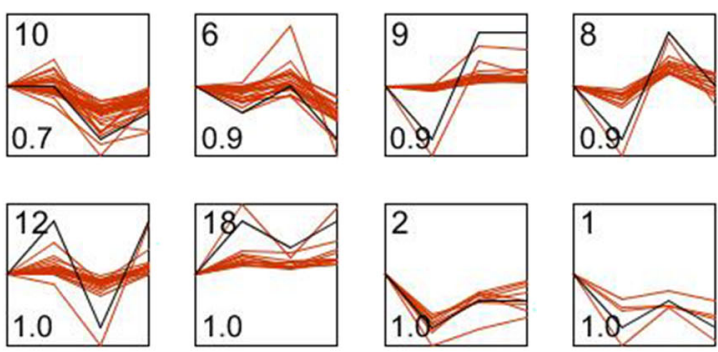

Filtered Gene Lis

Main Gene Table Interface Options..

Order Profiles By.

Order Clusters By

Compare.

Fig. 4 Dynamic expression pattern profiles of differentially expressed genes among treatments. Short Time-series Expression Miner (STEM) clustering analysis was performed to identify clusters; each cluster contained various numbers of DEGs with similar expression patterns. The top left-hand corner indicates the cluster ID. The lower left-hand corner contains the $P$-value of the number of assigned genes compared with the expected value. The black lines show model expression profiles. The red lines represent all individual gene expression profiles. The $x$-axis represents the dietary corn silage inclusion levels. The time series was log-normalized to start at 0 . The $y$-axes of all genes in a cluster box are at the same scale

of glycogenic substrates and/or energy resources could be provided to ruminants. It also suggests that a reasonable ruminal propionate content could also improve energy metabolism efficiency [36, 38].

As a feed with a much lower neutral detergent fiber (NDF) digestibility was fed, heifers should have had increased digesta in the gastrointestinal tract, thereby leading to increased gut fill in the high-forage groups compared to in the low-forage groups $[9,39]$. Consequently, the ADG and FE were greater in the low-forage groups (Table 2), which is consistent with the findings of previous studies [21, 40,41]. As heifers had a similar intake of'ME, the differences observed in ADG and FE, as well as in VFAs composition, suggest that the overall $\mathrm{ME}$ (of the entire body) might be reassigned to total heat energy (including heat increment and maintenance energy) and growth energy, when different $\mathrm{F}: \mathrm{C}$ diets are fed. Furthermore, these findings might suggest that the efficiency of energy utilization is greater in low-forage diets than in high-forage diets. Similarly, Reynolds et al. [6] found that $75 \%$ of forage-fed heifers had comparatively greater whole-body heat production and lower tissue energy retention. Nevertheless, it should be noted that the experimental period might not have been long enough to produce reliable estimates of $\mathrm{FE}$, and the general equation used to predict gut fill might not have been suitable for the specific situations of the present study. As a result, the long-term effects of limit-feeding on growth performance, as well as improved methods to monitor the actual BW of heifers should be considered in further studies.

\section{DEGs and pathways clustered in profile 19}

After digestion, the chemical constituents of the feed are further metabolized and subsequently transported to the liver [14]. Previous studies report that in order to utilize energy more effectively and efficiently when different F:C diets are fed, the liver has the capacity to regulate its metabolic activities, and even its size, to match wholebody energy requirements $[5,13]$. In the present study, some key genes associated with lipid metabolism, particularly cholesterol and steroid metabolism, were significantly altered in the liver when subjected to different $\mathrm{F}: \mathrm{C}$ diets.

Cholesterol performs a number of essential functions in the body. For example, it is a structural component of all cell membranes, thereby modulating their fluidity, and in specialized tissues, cholesterol is a precursor of bile acids, steroid hormones, and vitamin D [42]. It is critically important that the cells of the body have a steady, appropriate supply of cholesterol. The liver plays a central role in regulating cholesterol homeostasis [43]. The synthesis of cholesterol from acetyl-CoA involves more than 20 enzymatic reactions [44]. Among them, 


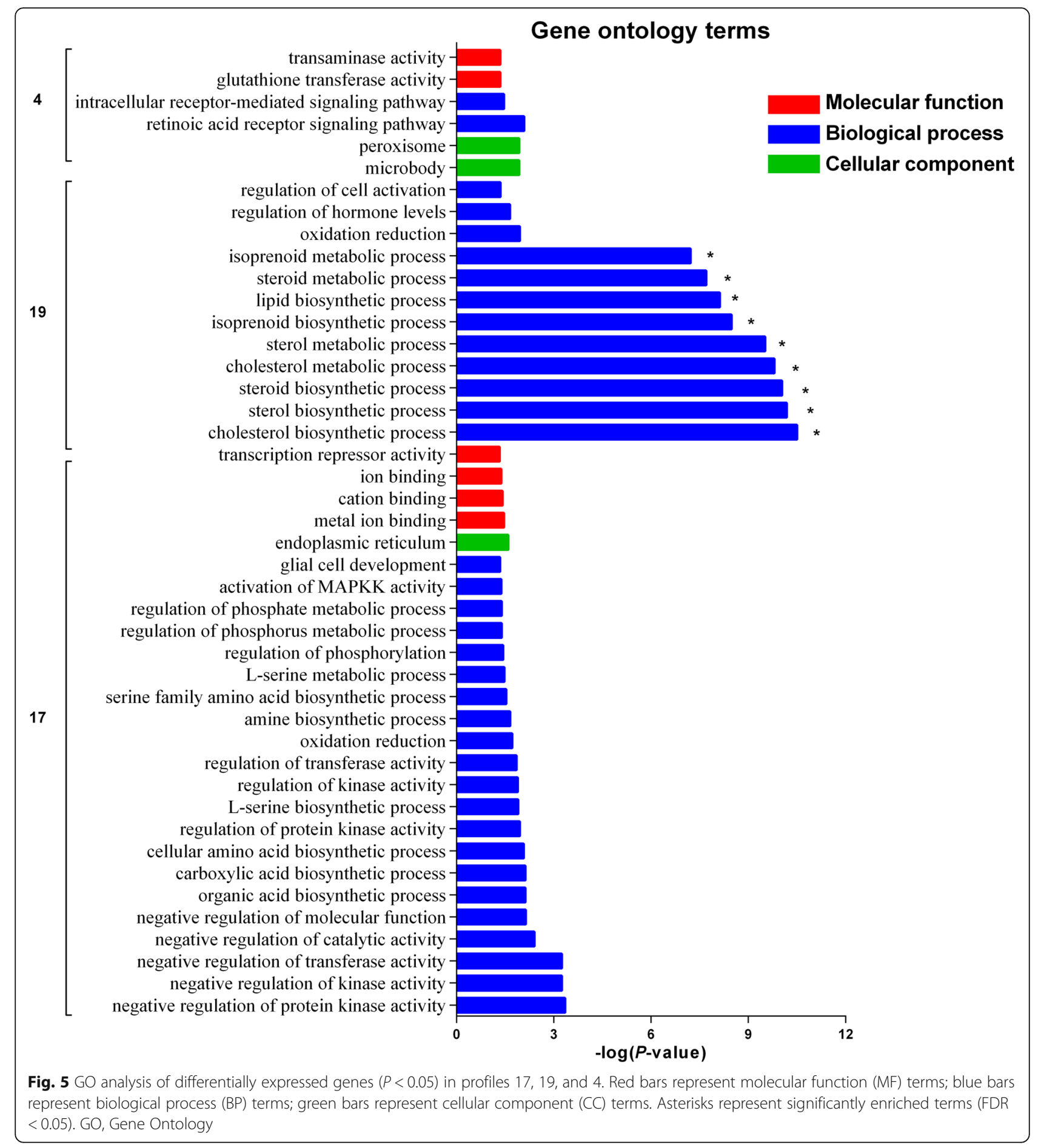

Table 6 Summary of the KEGG analysis of significant differentially expressed genes clustered in STEM

\begin{tabular}{lllll}
\hline Profile & Category ID & KEGG pathway & Genes & P-value \\
\hline 17 & KEGG-bta04115 & p53 signaling pathway & GADD45B, GADD45G, CDKN1A & 0.037508 \\
& KEGG-bta04010 & MAPK signaling pathway & HSPB1, ATF4, GADD45G, GADD45B, FGF21 & 0.038207 \\
19 & KEGG-bta00900 & Terpenoid backbone biosynthesis & HMGCR, HMGCS1, MVK, IDI1, MVD, FDPS & $2.68 \mathrm{E}-09$ \\
& KEGG-bta00100 & Steroid biosynthesis & DHCR7, LSS, MSMO1, SQLE & $5.75 \mathrm{E}-05$ \\
\hline
\end{tabular}




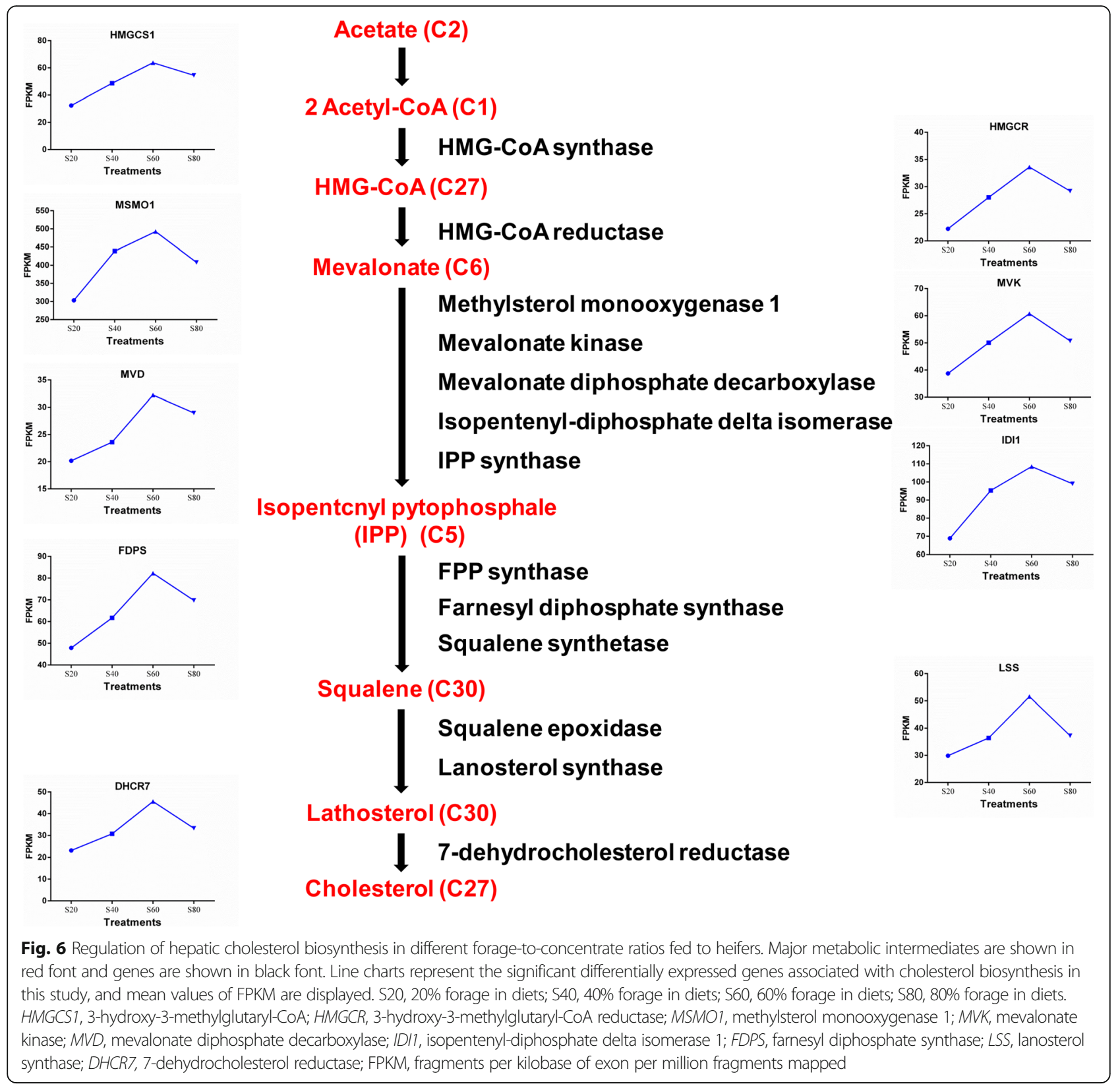

nine key genes, namely: HMGCS1, HMGCR, MSMO1, $M V K, M V D$, IDI1, FDPS, LSS, and DHCR7 that encode the enzymes involved in these reactions were found to be significantly differentially expressed in the present study (Fig. 6). Key enzymes of the cholesterol biosynthetic pathway that are also associated with rate-controlling steps have been identified as HMGCR, HMGCS1, and IDI1 [31, 43, 45]. Moreover, terpenoid backbone biosynthesis (KEGG map00900) shared some steps with cholesterol biosynthesis, and was one of the precursor steps for steroid biosynthesis (KEGG map00100) in the KEGG pathway analysis. This explains the simultaneous enrichment of these two pathways in the present study [46].
All of the aforementioned genes were enriched in profile 19 and showed a quadratic increase with increasing dietary forage levels, with the $\mathrm{S} 60$ group yielding the highest values (Fig. 6). This indicates that cholesterol synthesis was also quadratically increased. This finding was confirmed by the TC levels in the liver (Table 3). As one of the main precursors of cholesterol, about $60 \%-80 \%$ of acetate is absorbed in the rumen, and protein-mediated transport pathways play a major role in its absorption [47]. The reduced cholesterol synthesis observed in the S80 group could be due to the limited absorption capacity of acetate transporter proteins when excessive acetate is produced (Table 1). Therefore, experiments that measured 
the activity of protein-mediated transport pathways of acetate absorption in the rumen were warranted.

In the liver, cholesterol either becomes involved in bile synthesis, or is secreted in VLDL that is delivered to the systemic circulation [48]. The transporter proteins ABCG5 and ABCG8, both of which favor the secretion of cholesterol from the liver to the bile ducts [49], were found to be upregulated in the S60 group in comparison to the S80 group (Additional file 2: Table S4). On the other hand, the plasma concentration of HDL-C and TC showed a linear increase $(P \leq 0.07)$ with increasing levels of dietary forage (Table 6). The lower concentrations of VLDL-C observed in the 560 group could be attributed to the fact that they were processed in intermediatedensity lipoproteins and then metabolized to HDL.

\section{DEGs and pathways clustered in profile 17}

The genes HSPB1, ATF4, GADD45B, GADD45G, and FGF21 were differentially expressed and enriched in the MAPK signaling pathway in profile 17. The MAPKs both respond to extracellular stimuli (mitogens) and regulate various cellular activities [50,51]. In addition, MAPKs also play a pivotal role in inducing steroidogenic acute regulatory protein activity, steroidogenesis, and regulating cholesterol homeostasis $[46,52]$. When cows are subjected to feed restriction, cholesterol synthesis and MAPK activity are both inhibited [46]. By contrast, in the present study, both the MAPK signaling pathway and steroid biosynthesis were stimulated with increasing dietary forage levels, indicating that the MAPK signaling pathway was executing its role in regulating cholesterol homeostasis.

In this study, GADD45B, GADD45G, and CDKN1A were also significantly differentially expressed and enriched in the p53 signaling pathways of profile 17 (Table 4). The GADD45 genes are important for intracellular communication in the immune system, and were found to be upregulated in the liver of cattle that had higher serum concentrations of cholesterol, or lower residual feed intake, as well as lower levels of cellular growth and proliferation, and lipid metabolism [18, 50]. The p53 signaling pathway and MAPK signaling pathway shared the same significant DEGs (GADD45B and GADD45G) in the present study. Thus, it is reasonable to infer that the changes observed in the p53 signaling pathway might be related to cholesterol biosynthesis. However, this inference should be made with caution, as only three genes were enriched in the p53 signaling pathway in the present study.

However, the synthesis of cholesterol is a highly energy-consuming process that requires $36 \mathrm{~mol}$ of ATP to produce $1 \mathrm{~mol}$ of cholesterol [53]. In addition, cholesterol metabolism reportedly has a closely relationship with whole-body energy partitioning [43, 54]. Previous studies have also reported that the liver tends to spare energy by inhibiting the biosynthesis of cholesterol to provide energy and glucose for the lactating mammary gland during feed deprivation $[46,55]$. It has been suggested that lipid metabolism, especially cholesterol and sterol metabolism, can be an important mechanism to achieve energy partitioning and reassignment in cows, especially when the energy supply is required for certain physiological states, or changed by dietary composition $[13,43,54]$. Therefore, it is reasonable to infer that the increased cholesterol synthesis from acetate observed in the present study, might be one of the main reasons for the reduced efficiency of energy utilization observed in high-forage-fed heifers.

The FGF21 protein has been identified as a novel hormonal factor produced by the liver that is involved in the regulation of metabolic homeostasis and energy balance (particularly the processes of glucose and lipid metabolism) in cattle $[56,57]$. Recent studies have also reported that bovine FGF21 gene expression or circulating concentrations of FGF21 are significantly associated with $\mathrm{BW}$ and/or ADG and residual feed intake (RFI) rank in heifers $[58,59]$. In the present study, FGF21 mRNA expression increased with increasing dietary forage levels, and this could have occurred as a consequence of energy reassignment. This finding is consistent with the findings of previous studies that have demonstrated the response of FGF21 to changes in energy utilization and feed intake $[56,57]$.

\section{Other important DEGs and pathways}

In accordance with previous reports [18, 60, 61], our study also found that the metabolism of xenobiotics by cytochrome P450; drug metabolism; steroid hormone biosynthesis; alanine, aspartate and glutamate metabolism; glutathione metabolism; and retinol metabolism pathways (Fig. 3) were all significantly enriched in the liver and might have been involved in the regulation of feed efficiency.

Alanine and glutamine are the most glucogenic, and account for $40 \%-60 \%$ of the glucose formed from amino acids in ruminants [62, 63]. In this study, plasma ALT activity was increased with increasing dietary forage levels, indicating that the amount of glucose produced from alanine might be increased when heifers consume high-forage diets. This finding is in line with the changes observed in alanine, aspartate and glutamate metabolism and glutathione metabolic pathways in the liver. McCabe et al. [17] reported that CYP11A1, UGT2a1, SULTE1, and CYP7A1 were altered in the steroid hormone biosynthesis pathway when cows were subjected to severe negative energy balance. In the present study, these four genes were all found to be altered in the same pathway (Additional file 2: Table S4). The CYP7A1 gene has the 
ability to catalyze the rate-limiting step of the conversion of cholesterol to bile acids [17]. The CYP11A1 gene is also known as cytochrome P450, and is closely associated with the metabolism of xenobiotics (such as drugs), and lipid homeostasis (including cholesterol, steroids, vitamin $\mathrm{D}$, and bile acids) [17, 18, 60]. Tizioto et al. [61] showed that glutathione S-transferases (MSTs) that are associated with the catalysis of certain reactions by cytochrome P450 proteins, and the synthesis of cholesterol, steroids, and other lipids, are upregulated in inefficient cattle. These results further suggest that the efficiency of energy utilization might be reduced in highforage-fed heifers.

\section{Conclusions}

In this study, lower levels of ADG and FE were observed in high-forage-fed heifers, indicating that different mechanisms of energy utilization efficiency might have been involved. Hepatic cholesterol biosynthesis and steroid biosynthesis, both of which are high energy-consumption activities, as well as liver and plasma concentrations of TC, were significantly increased in heifers fed high-forage diets. The MAPK signaling pathway, which may have an important role in the regulation of steroid metabolism, also showed a linear increase with increasing dietary forage levels. Therefore, increased hepatic lipid metabolism might be responsible for the lower energy utilization efficiency observed in the heifers fed high-forage diets. This study might be useful in the future identification of individual heifers within the same dietary group that are high-efficiency phenotypes, using the upregulation of cholesterol metabolism as a proxy. In conclusion, the results of the present study provide an insight into the biology of energy utilization in heifers, and they have the potential to promote a favorable strategy to improve feed efficiency in ruminants.

\section{Additional files}

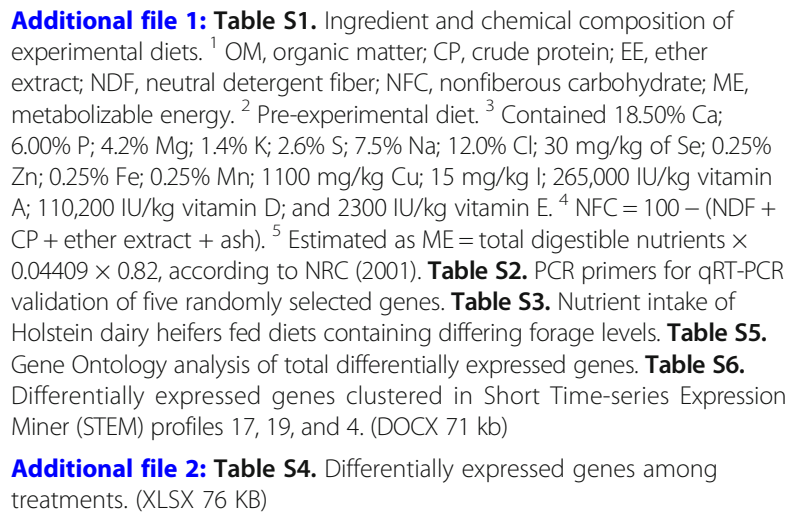

Additional file 2: Table S4. Differentially expressed genes among treatments. (XLSX 76 KB)

\section{Abbreviations}

A:P: Acetate:propionate; ABCG5: ATP binding cassette subfamily G member 5 : ABCG8: ATP binding cassette subfamily G member 8; ACACA: Acetyl-CoA carboxylase alpha; ADG: Average daily gain; AGMO: Alkylglycerol monooxygenase; ALT: Alanine aminotransferase; ATF4: Activating transcription factor 4; BP: Biological process; BW: Body weight; CC: Cellular component; CDKN1A: Cyclin-dependent kinase inhibitor 1A; CP: Crude protein; CYP11A1: Cytochrome P450, family 11, subfamily A, polypeptide 1; DEGs: Differentially expressed genes; DHCR7: 7-dehydrocholesterol reductase; DM: Dry matter; DMI: Dry matter intake; ELISA: Enzyme linked immunosorbent assay; F:C: Forage:concentrate ratios; FADS2: Fatty acid desaturase 2; FC: Fold change; FDPS: Farnesyl diphosphate synthase; FE: Feed efficiency; FGF21: Fibroblast growth factor 21; FPKM: Fragments per kilobase of exon per million fragments mapped; GADD45B: Growth arrest and DNA damage inducible beta; GADD45G: Growth arrest and DNA damage inducible gamma; GO: Gene ontology; GOT1: Glutamic-oxaloacetic transaminase 1; HDL-C: High density lipoprotein cholesterol; HMGCR: 3-hydroxy-3methylglutaryl-CoA reductase; HMGCS1: 3-hydroxy-3-methylglutaryl-CoA; HSPB1: Heat shock protein family B (small) member 1; IDI1: Isopentenyldiphosphate delta isomerase 1; KEGG: Kyoto Encyclopedia of Genes and Genomes database; LDL-C: Low density lipoproteins cholesterol; LSS: Lanosterol synthase; MAPK: Mitogen-activated protein kinase; ME: Metabolizable energy; MF: Molecular function;

MOGAT1: Monoacylglycerol O-acyltransferase 1; MSMO1: Methylsterol monooxygenase 1; MVD: Mevalonate diphosphate decarboxylase; MVK: Mevalonate kinase; P2RX7: Purinergic receptor P2X, ligand gated ion channel 7; PCK1: Phosphoenolpyruvate carboxykinase 1; PDV: Portal-drained viscera; PTGS1: Prostaglandin-endoperoxide synthase 1; SEM: Standard error of the means; SOAT2: Sterol O-acyltransferase 2; SRA: Sequence read archive; STEM: Short Time-series Expression Miner; TC: Total cholesterol; TG: Total triglycerides; TMR: Total mixed ration; VFAs: Volatile fatty acids; VLDL-C: Very low density lipoproteins cholesterol

\section{Acknowledgments}

The authors thank the Beijing Sanyuan Lvhe Dairy Group for providing the trial site and animals. Special thanks go to the staff of Beijing Jinxing Dairy Farm for their assistance in keeping the animals and sampling. We thank Dr. Ying Yu for advice on RNA extraction and preprocessing the data.

\section{Funding}

This work was supported by the National Nature Science Foundation (31402099), National Dairy Industry and Technology System (CARS-37), and National Key R\&D Program of China (S2016G4513). The funding body has not participated in or interfered with the research.

\section{Availability of data and materials}

All sequencing data (fastq files) generated in the present study are available in the NCBI Sequence Read Archive (SRA) (https://www.ncbi.nlm.nih.gov/sra/) with accession number SRP110260.

\section{Authors' contributions}

YW and SL designed the study; HS, JZ, SJ, and HZ conducted the animal trial and collected samples; JZ and HS prepared libraries, analyzed data, and wrote the manuscript. YW, ZC, and SL revised the manuscript. HS and JZ contributed equally to this study. All authors read and approved the final manuscript.

\section{Ethics approval and consent to participate}

Animal care for the experiment complied with the Regulations for the Administration of Affairs Concerning Experimental Animals, National Committee of Science and Technology of China (14 November 1988) and Instructive Notions with Respect to Caring for Experimental Animals, Ministry of Science and Technology of China (13 September 2006). Animal procedures were approved by the Ethical Committee of the College of Animal Science and Technology of China Agricultural University.

\section{Consent for publication}

Not applicable.

\section{Competing interests}

The authors declare that they have no competing interests. 


\section{Publisher's Note}

Springer Nature remains neutral with regard to jurisdictional claims in published maps and institutional affiliations.

\begin{abstract}
Author details
${ }^{1}$ State Key Laboratory of Animal Nutrition, Beijing Engineering Technology Research Center of Raw Milk Quality and Safety Control, College of Animal Science and Technology, China Agricultural University, No.2 Yuanmingyuan West Road, Haidian, Beijing 100193, People's Republic of China. ${ }^{2}$ Department of Animal and Poultry Science, University of Saskatchewan, Saskatoon, SK S7N 5A8, Canada.
\end{abstract}

Received: 16 October 2017 Accepted: 5 February 2018 Published online: 17 February 2018

\section{References}

1. Thornton PK. Livestock production: recent trends, future prospects. Philos Trans R Soc Lond Ser B Biol Sci. 2010;365(1554):2853-67.

2. Russell JB, Rychlik JL. Factors that alter rumen microbial ecology. Science. 2001:292(5519):1119-22.

3. Pirlo G, Capelletti M, Marchetto G. Effects of energy and protein allowances in the diets of prepubertal heifers on growth and milk production. J Dairy Sci. 1997:80(4):730-9

4. Lemenager RP, Smith WH, Martin TG, Singleton WL, Hodges JR. Effects of winter and summer energy levels on heifer growth and reproductive performance. J Anim Sci. 1980:51(4):837-42.

5. Wang YJ, Wood KM, Martin L, Holligan S, Kelly N, McBride BW, Fan MZ, Swanson KC. Effect of dietary corn silage inclusion on visceral organ mass, cellularity, and the protein expression of ATP synthase, Na+/K+-ATPase, proliferating cell nuclear antigen and ubiquitin in feedlot steers. Can J Anim Sci. 2009:89(4):503-12.

6. Reynolds CK, Henry FT, Reynolds PJ. Effects of diet forage-to-concentrate ratio and intake on energy metabolism in growing beef heifers: whole body energy and nitrogen balance and visceral heat production. J Nutr. 1991;121(7):994-1003.

7. Burrin DG, Ferrell CL, Eisemann JH, Britton RA, Nienaber JA. Effect of level of nutrition on splanchnic blood flow and oxygen consumption in sheep. $\mathrm{Br} J$ Nutr. 1989;62(01):23-34.

8. Lascano GJ, Koch LE, Heinrichs AJ. Precision-feeding dairy heifers a high rumen-degradable protein diet with different proportions of dietary fiber and forage-to-concentrate ratios. J Dairy Sci. 2016;99(9):7175-90.

9. Suarez-Mena FX, Lascano GJ, Rico DE, Heinrichs AJ. Effect of forage level and replacing canola meal with dry distillers grains with solubles in precision-fed heifer diets: digestibility and rumen fermentation. J Dairy Sci. 2015;98(11):8054-65

10. Zhang J, Shi H, Wang Y, Li S, Cao Z, Ji S, He Y, Zhang H. Effect of dietary forage to concentrate ratios on dynamic profile changes and interactions of ruminal microbiota and metabolites in Holstein heifers. Front Microbiol. 2017;8:2206.

11. Zanton Gl, Heinrichs AJ. Digestion and nitrogen utilization in dairy heifers limit-fed a low or high forage ration at four levels of nitrogen intake. J Dairy Sci. 2009;92(5):2078-94.

12. Zanton Gl, Heinrichs AJ. Efficiency and rumen responses in younger and older Holstein heifers limit-fed diets of differing energy density. J Dairy Sci. 2016:99(4):2825-36.

13. Huntington GB. Energy metabolism in the digestive tract and liver of cattle: influence of physiological state and nutrition. Reprod Nutr Dev. 1990;30(1):35-47.

14. Keogh K, Kenny DA, Cormican P, Kelly AK, Waters SM. Effect of dietary restriction and subsequent re-alimentation on the transcriptional profile of hepatic tissue in cattle. BMC Genomics. 2016;17(1):244.

15. Raz T, Kapranov P, Lipson D, Letovsky S, Milos PM, Thompson JF. Protocol dependence of sequencing-based gene expression measurements. PLoS One. 2011;6(5):e19287.

16. Ozsolak F, Milos PM. RNA sequencing: advances, challenges and opportunities. Nat Rev Genet. 2011;12(2):87-98.

17. McCabe M, Waters S, Morris D, Kenny D, Lynn D, Creevey C. RNA-seq analysis of differential gene expression in liver from lactating dairy cows divergent in negative energy balance. BMC Genomics. 2012;13(1):193.

18. Alexandre PA, Kogelman LJ, Santana MH, Passarelli D, Pulz LH, FantinatoNeto P, Silva SL, Leme PR, Strefezzi RF, Coutinho LL, et al. Liver transcriptomic networks reveal main biological processes associated with feed efficiency in beef cattle. BMC Genomics. 2016;17(1):311.

19. NRC: Nutrient requirements of dairy cattle. Washington DC: Natl. Acad. Sci.; 2001

20. Broderick GA, Kang JH. Automated simultaneous determination of ammonia and total amino acids in ruminal fluid and in vitro media. J Dairy Sci. 1980; 63(1):64-75.

21. Lascano GJ, Zanton Gl, Suarez-Mena FX, Heinrichs AJ. Effect of limit feeding high- and low-concentrate diets with Saccharomyces Cerevisiae on digestibility and on dairy heifer growth and first-lactation performance. J Dairy Sci. 2009;92(10):5100-10.

22. Williams CB, Keele JW, Waldo DR. A computer model to predict empty body weight in cattle from diet and animal characteristics. J Anim Sci. 1992;70(10):3215-22.

23. Greenfield RB, Cecava MJ, Johnson TR, Donkin SS. Impact of dietary protein amount and rumen undegradability on intake, peripartum liver triglyceride, plasma metabolites, and milk production in transition dairy cattle. J Dairy Sci. 2000;83(4):703-10.

24. Zhou Z, Garrow TA, Dong X, Luchini DN, Loor JJ. Hepatic activity and transcription of betaine-homocysteine methyltransferase, methionine synthase, and cystathionine synthase in Periparturient dairy cows are altered to different extents by supply of methionine and choline. J Nutr. 2017; 147(1):11-9.

25. Trapnell C, Williams BA, Pertea G, Mortazavi A, Kwan G, Van Baren MJ, Salzberg SL, Wold BJ, Pachter L. Transcript assembly and quantification by RNA-Seq reveals unannotated transcripts and isoform switching during cell differentiation. Nat Biotechnol. 2010;28(5):511-5.

26. Dennis Jr G, Sherman BT, Hosack DA, Yang J, Gao W, Lane HC, Lempicki RA DAVID: database for annotation, visualization, and integrated discovery. Genome Biol 2003:4(5):P3.

27. Ernst J, Bar-Joseph Z. STEM: a tool for the analysis of short time series gene expression data. BMC Bioinformatics. 2006;7(1):1.

28. Ghandhi SA, Sinha A, Markatou M, Amundson SA. Time-series clustering of gene expression in irradiated and bystander fibroblasts: an application of FBPA clustering. BMC Genomics. 2011;12(1):1.

29. Zhang J, Zhao S, Zhang Y, Sun P, Bu D, Wang J. New primers targeting fulllength ciliate $18 \mathrm{~S}$ rRNA genes and evaluation of dietary effect on rumen ciliate diversity in dairy cows. Curr Microbiol. 2015;71(6):650-7.

30. Xing K, Zhu F, Zhai L, Liu H, Wang Z, Hou Z, Wang C. The liver transcriptome of two full-sibling Songliao black pigs with extreme differences in backfat thickness. J Anim Sci Biotechnol. 2014;5(1):32.

31. Viturro E, Koenning M, Kroemer A, Schlamberger G, Wiedemann S, Kaske M, Meyer $\mathrm{HH}$. Cholesterol synthesis in the lactating cow: induced expression of candidate genes. J Steroid Biochem Mol Biol. 2009;115(1-2):62-7.

32. Dijkstra J. Production and absorption of volatile fatty acids in the rumen. Livest Prod Sci. 1994;39(1):61-9.

33. Bickerstaffe $\mathrm{R}$, Annison EF. The metabolism of glucose, acetate, lipids and amino acids in lactating dairy cows. J Agric Sci. 1974;82:71-85.

34. Remond D, Bernard L, Chauveau B, Noziere P, Poncet C. Digestion and nutrient net fluxes across the rumen, and the mesenteric- and portaldrained viscera in sheep fed with fresh forage twice daily: net balance and dynamic aspects. Br J Nutr. 2003;89(5):649-66.

35. Young JW. Gluconeogenesis in cattle: significance and methodology. J Dairy Sci. 1977;60(1):1-15.

36. Moe PW. Energy metabolism of dairy cattle. J Dairy Sci. 1981;64:1120-39.

37. Armstrong DG, Blaxter KL. The utilization of acetic propionic and butyric acids by fattening sheep. Br J Nutr. 1957;11(4):413-25.

38. van Knegsel AT, van den Brand H, Dijkstra J, Tamminga S, Kemp B. Effect of dietary energy source on energy balance, production, metabolic disorders and reproduction in lactating dairy cattle. Reprod Nutr Dev. 2005:45(6):665-88.

39. Zanton Gl, Heinrichs AJ. The effects of controlled feeding of a high-forage or high-concentrate ration on heifer growth and first-lactation milk production. J Dairy Sci. 2007;90(7):3388-96.

40. Pino F, Heinrichs AJ. Sorghum forage in precision-fed dairy heifer diets. J Dairy Sci. 2017;100(1):224-35.

41. Hoffman PC, Simson CR, Wattiaux M. Limit feeding of gravid Holstein heifers: effect on growth, manure nutrient excretion, and subsequent early lactation performance. J Dairy Sci. 2007;90(2):946-54.

42. Goedeke L, Fernandez-Hernando C. Regulation of cholesterol homeostasis. Cell Mol Life Sci. 2012;69(6):915-30. 
43. Kessler EC, Gross JJ, Bruckmaier RM, Albrecht C. Cholesterol metabolism, transport, and hepatic regulation in dairy cows during transition and early lactation. J Dairy Sci. 2014;97(9):5481-90.

44. Kortner TM, Bjorkhem I, Krasnov A, Timmerhaus G, Krogdahl A. Dietary cholesterol supplementation to a plant-based diet suppresses the complete pathway of cholesterol synthesis and induces bile acid production in Atlantic salmon (Salmo Salar L.). Br J Nutr. 2014;111(12):2089-103.

45. Breitling R, Laubner D, Clizbe D, Adamski J, Krisans SK. Isopentenyldiphosphate isomerases in human and mouse: evolutionary analysis of a mammalian gene duplication. J Mol Evol. 2003;57(3):282-91.

46. Akbar H, Bionaz M, Carlson DB, Rodriguez-Zas SL, Everts RE, Lewin HA, Drackley JK, Loor JJ. Feed restriction, but not I-carnitine infusion, alters the liver transcriptome by inhibiting sterol synthesis and mitochondrial oxidative phosphorylation and increasing gluconeogenesis in mid-lactation dairy cows. J Dairy Sci. 2013;96(4):2201-13.

47. Aschenbach JR, Bilk S, Tadesse G, Stumpff F, Gabel G. Bicarbonatedependent and bicarbonate-independent mechanisms contribute to nondiffusive uptake of acetate in the ruminal epithelium of sheep. Am J Physiol Gastrointest Liver Physiol. 2009;296(5):G1098-107.

48. Desvergne B, Michalik L, Wahli W. Transcriptional regulation of metabolism. Physiol Rev. 2006:

49. Abumrad NA, Davidson NO. Role of the gut in lipid homeostasis. Physiol Rev. 2012;92(3):1061-85.

50. Chen Y, Gondro C, Quinn K, Herd RM, Parnell PF, Vanselow B. Global gene expression profiling reveals genes expressed differentially in cattle with high and low residual feed intake. Anim Genet. 2011;42(5):475-90.

51. Pearson G, Robinson F, Beers Gibson T, Xu BE, Karandikar M, Berman K, Cobb MH. Mitogen-activated protein (MAP) kinase pathways: regulation and physiological functions. Endocr Rev. 2001;22(2):153-83.

52. Singh RP. One-way cross-talk between p38(MAPK) and p42/(44MAPK). Inhibition of $\mathrm{p38(MAPK)}$ induces low density lipoprotein receptor expression through activation of the p42/44(mapk) cascade. J Biol Chem. 1999;274(28):19593-600

53. Jia L, Betters JL, Yu L. Niemann-pick C1-like 1 (NPC1L1) protein in intestinal and hepatic cholesterol transport. Annu Rev Physiol. 2011;73:239-59.

54. Schlegel G, Ringseis R, Keller J, Schwarz FJ, Eder K. Changes in the expression of hepatic genes involved in cholesterol homeostasis in dairy cows in the transition period and at different stages of lactation. J Dairy Sci. 2012;95(7):3826-36.

55. Loor JJ, Everts RE, Bionaz M, Dann HM, Morin DE, Oliveira R, Rodriguez-Zas SL, Drackley JK, Lewin HA. Nutrition-induced ketosis alters metabolic and signaling gene networks in liver of periparturient dairy cows. Physiol Genomics. 2007;32(1):105-16.

56. Schlegel G, Ringseis R, Keller J, Schwarz FJ, Windisch W, Eder K. Expression of fibroblast growth factor 21 in the liver of dairy cows in the transition period and during lactation. J Anim Physiol Anim Nutr (Berl). 2013;97(5):820-9.

57. Akbar H, Batistel F, Drackley JK, Loor JJ. Alterations in hepatic FGF21, co-regulated genes, and upstream metabolic genes in response to nutrition, ketosis and inflammation in Peripartal Holstein cows. PLoS One. 2015;10(10):e0139963.

58. Sun X-M, Li M-X, Li A-M, Lan X-Y, Lei C-Z, Ma W, Hua L-S, Wang J, Hu S-R, Chen H. Two novel intronic polymorphisms of bovine FGF21 gene are associated with body weight at 18 months in Chinese cattle. Livest Sci. 2013;155(1):23-9.

59. Yu J, Zhao L, Wang A, Eleswarapu S, Ge X, Chen D, Jiang H. Growth hormone stimulates transcription of the fibroblast growth factor 21 gene in the liver through the signal transducer and activator of transcription 5. Endocrinology. 2012;153(2):750-8.

60. Salleh MS, Mazzoni G, Hoglund JK, Olijhoek DW, Lund P, Lovendahl P, Kadarmideen HN. RNA-Seq transcriptomics and pathway analyses reveal potential regulatory genes and molecular mechanisms in high- and lowresidual feed intake in Nordic dairy cattle. BMC Genomics. 2017;18(1):258.

61. Tizioto PC, Coutinho LL, Decker JE, Schnabel RD, Rosa KO, Oliveira PS, Souza MM, Mourao GB, Tullio RR, Chaves AS, et al. Global liver gene expression differences in Nelore steers with divergent residual feed intake phenotypes. BMC Genomics. 2015;16:242.

62. Felig P, Pozefsk T, Marlis E, Cahill GF. Alanine: key role in gluconeogenesis. Science. 1970;167(3920):1003-4.

63. Moundras C, Remesy C, Bercovici D, Demigne C. Effect of dietary supplementation with glutamic-acid or glutamine on the splanchnic and muscle metabolism of Glucogenic amino-acids in the rat. J Nutr Biochem. 1993:4(4):222-8.

\section{Submit your next manuscript to BioMed Central and we will help you at every step:}

- We accept pre-submission inquiries

- Our selector tool helps you to find the most relevant journal

- We provide round the clock customer support

- Convenient online submission

- Thorough peer review

- Inclusion in PubMed and all major indexing services

- Maximum visibility for your research

Submit your manuscript at www.biomedcentral.com/submit 